\title{
Study of the intima-media thickening in carotid arteries of healthy elderly with high blood pressure and elderly with high blood pressure and dyslipidemia
}

\author{
Elizabete Viana de Freitas \\ Andréa Araújo Brandão \\ Roberto Pozzan \\ Maria Eliane Magalhães \\ Márcia Castier \\ Airton Pires Brandão \\ Cardiology Department, Pedro \\ Ernesto University Hospital, State \\ University of Rio de Janeiro, Brazil
}

\begin{abstract}
Objective: The objective of this study was to assess the mean intima-media thickening of carotid arteries of elderly subjects, and its relationship with age, anthropometric measurements, high systolic blood pressure and dyslipidemia.

Methods: In this investigation, 129 subjects were enrolled between 1995 and 1998, age ranging from 29 to 94 years. They were assigned to one of 4 groups, including 2 control groups (group I, of healthy younger subjects; group II of healthy elderly subjects). Groups III and IV included those who presented with isolated systolic hypertension (ISH), and ISH and dyslipidemia, respectively. All subjects were submitted to a medical interview, lab tests with measurement of cholesterol levels, electrocardiogram, and carotid ultrasound. The ultrasound included measurement of the intima-media thickening (IMT) of the carotid arteries, the right carotid artery (RCA) and left carotid artery (LCA), and assessment of the presence of plaques. Blood fat and glucose were measured by a standard method. The results were compared among the groups through statistical tests. The tests employed were: Chi-Square, Pearson's and Likelihood Ratio, Student's t, Mann-Whitney; ANOVA followed by Tukey's test, Kruskal-Wallis nonparametric test, and test for multiple comparisons and Odds Ratio determination (OR).
\end{abstract}

Results: In this investigation, a positive association was observed between aging and IMT. In relation to systolic hypertension, a significant association was observed with IMT (IMT-RCA $p=0.0034$; IMT-LCA $p=0.0196$; IMT-RLCA $p=0.0299$ ), and with the presence of plaques (PlaqueR $p=0.0110$; PlaqueL $p=0.0294$; PlaqueRL $p=0.0040$ ).

Conclusion: This investigation evidenced the important role of aging in IMT, and of systolic hypertension in the IMT and presence of plaque. However, further studies are needed for a better understanding of the actual role of risk factors in aging.

Keywords: aging, elderly, carotid arteries, high blood pressure

\section{Introduction}

The aging of the population is, currently, a major phenomenon, drawing the attention of a number of investigators (Kalache et al 1987; OMS 1997). The significant increase of life expectancies over the past few decades, in addition to social and economic consequences, has lead to a major change in the morbidity and mortality profile of elders, the so-called, Epidemiologic Transition. The impact on health services is highly important, as individuals of 60 years or older present high prevalence of chronic degenerative diseases, which cause dependency and impairment (Lewis 1993). According to the American Heart Association Statistical Update (2007), from the 79400000 American adults with one or more cardiovascular disease (CVD), it is estimated that 37500000 are 65 years old or older. These figures reflect the importance of the atherosclerotic process in the elderly, highlighting the 
need for prevention and detection. However, studies in the field of geriatrics, still at an early stage, are uncertain as to the predictive value of risk factors (RF) for CVD in the elderly, particularly in those older than 75 years. Based on this, some authors are currently studying the relationship between the process of atherosclerosis in the elderly and a number of RF (Kannel 1996; Howard et al 1997; Williams et al 2002; Davidson et al 2003). Aging, high blood pressure (BP), dyslipidemia, and obesity are among the RF that may lead to endothelial dysfunction and, therefore, to vascular changes.

A number of trials have indeed shown a clear association between dyslipidemia, and high BP and intima-media thickness (IMT) (Luscher et al 1991, 1992; Endemann and Schiffrin 1992; Fabris et al 1994; Bilato and Crow 1996; Cutler 1996; La Rosa 1996; O'Leary et al 1996; Howard et al 1997; Wilt et al 1997; Millio et al 2006; Fletcher et al 2007). The ageing process by itself causes changes both in the architecture and constitution of the vascular wall. The aging endothelium releases less nitric oxide (NO), which is important for vascular relaxation. The collagen increases, whereas elastine becomes progressively disrupted, thinner, and often fragments itself. Deposits of fat and calcium are formed, with concurrent loss of elasticity. These agingrelated vascular changes have important medical implications in CVD pathogenesis (Libby 2006). The pathophysiology of the arterial hypertension is highly complex, with a number of related factors, including changes in a number of systems, even affecting the relation between the thickness of the arterial wall and its lumen. A number of noninvasive studies of the carotids with the use of ultrasound have shown the role of RF, high BP among them, in the genesis of IMT (Suurkula et al 1994, 1996; Bonithon-Kopp et al 1996; Panza 1997; Wilson et al 1997; Wang et al 2006). In the elderly population, it has been observed that the prevalence of isolated systolic hypertension (ISH) reaches about 50\% of these individuals, and seems to be more associated to cardiovascular (CV) events than to systolic and diastolic or isolated diastolic hypertension (JNC VIII 2003; Wang et al 2006).

At an early stage, atherosclerosis is characterized by an accumulation of macrophages, involving remainders of low density lipoprotein cholesterol (LDL-c) and cholesterol in the subendothelial space of the vessel (Noll and Luscher 1994; Baldassare et al 1996; Jorge 1997; III Brazilian Consensus of Dyslipidemia 2001; Endemann and Schiffrin 2004). Even though a consensus seems to have been reached regarding the influence of lipoproteins on the onset of CVD, their role as a predictor of CV RF in the elderly is still being discussed (Luscher et al 1991, 1992; Fabris et al 1994; Bilato and Crow 1996; Cutler 1996; La Rosa 1996; O’Leary et al 1996; Howard et al 1997; Williams et al 2002; Endemann and Schiffrin 2004; Millio et al 2006; Fletcher et al 2007) On the other hand, evidence that hyperlipemia leads to carotid IMT (Bonithon-Kopp et al 1996) has triggered a number of studies with ultrasound assessment, which have shown a positive relationship between carotid IMT and LDL-c, even in elderly subjects.

Within this framework, the purpose of this investigation was: 1) to assess the intima-media complex of carotid arteries through ultrasound examination in healthy elderly, elderly with ISH, and elderly with ISH and dyslipidemia, and 2) to establish, among the variables age, anthropometric measurements, high BP, and dyslipidemia, those that correlate the best with the IMT of the investigated population.

\section{Subjects and methods Subjects}

For this investigation, 129 subjects were enrolled between 1995 e 1998, divided in 4 groups (Table 1): 2 control groups or healthy individuals, 1 group of patients with ISH, and 1 group of patients with ISH and dyslipidemia. 30 subjects were assigned to group I, consisting of 19 males (63.3\%) and 11 females (36.6\%), according to the following inclusion criteria: (1) age between 18 and 35 years, (2) normotensives, (3) normocholesterolemics, and (4) not using CV drugs. Group II included 30 subjects, consisting of 10 males $(33.33 \%)$ and 20 females (66.66\%), according to the following inclusion criteria: (1) age of 60 or older, (2) normotensives, (3) normocholesterolemics, and (4) not using $\mathrm{CV}$ drugs. 30 patients to group III were assigned, including 12 males (40\%) and 18 females (60\%); eligibility criteria included: (1) age 60 years or older, (2) presence of ISH, (3) normocholesterolemics, and (4) use of antihypertensive agents limited to angiotensina-converting enzyme (ACE) inhibitor and/or diuretics. Lastly, 39 subjects were assigned to group IV, consisting of 15 males (38.46\%) and 24 females (61.54\%), who met the eligibility criteria of: (1) age of 60 years or older, (2) presence ISH, (3) presence of hyperlipemia, and (4) use of antihypertensive agents limited to angiotensina-converting enzyme (ACE) inhibitor, angiotensina receptor blockers II (AT 1 blocker) and/or diuretics (Table 1). Exclusion criteria included: (1) age between 36 and 59 years, (2) use of lipidlowering drugs or other agents that could influence the results of the tests, (3) cancer or any severe chronic-degenerative diseases, (4) impairment, (5) dementia, (6) renal failure, (7) 
Table I The inclusion criteria

\begin{tabular}{|c|c|c|c|c|}
\hline & Age (Years) & Blood pressure & Lipids & Drugs \\
\hline $\begin{array}{l}\text { Group I } \\
n=30 \\
\text { Male = } 19 \\
\text { Female = II }\end{array}$ & Between 18 and 35 & normal & normal & Without drugs $\mathrm{CV}$ action \\
\hline $\begin{array}{l}\text { Group II } \\
n=30 \\
\text { Male }=10 \\
\text { Female }=20\end{array}$ & 60 or more years & normal & normal & Without drugs $\mathrm{CV}$ action \\
\hline $\begin{array}{l}\text { Group III } \\
n=30 \\
\text { Male }=12 \\
\text { Female }=18\end{array}$ & 60 or more years & isolated systolic hypertension & normolypidemia & $\begin{array}{l}\text { ACE inhibitor or } \mathrm{AT} \text {, } \\
\text { and/or/or diuretics }\end{array}$ \\
\hline Group IV & 60 or more years & isolated systolic hypertension & dyslipidemia & $\begin{array}{l}\mathrm{ACE} \text { inhibitor or } \mathrm{AT}_{\mathrm{T}} \\
\text { and/or/or diuretics }\end{array}$ \\
\hline $\begin{array}{l}n=39 \\
\text { Male }=15 \\
\text { Female }=24\end{array}$ & & & & \\
\hline
\end{tabular}

Abbreviations: n, number; CV, cardiovascular; ACE, angiotensin-converting enzyme; $\mathrm{AT}$, angiotensin receptor I.

secondary hypertension, (8) diabetes mellitus (DM), and (9) triglycerides higher than $400 \mathrm{mg} / \mathrm{dL} \%$.

\section{Methodology}

The eligible subjects, after being informed about the investigation and agreeing to take part in it, were submitted to a medical interview, medical examination and laboratory tests. A standard questionnaire was applied to collect demographic data, a history of previous medical conditions, and a detailed inquiry on medication currently being used. Finally, a complete physical examination was performed, and body mass index (BMI) was calculated $\left(\mathrm{kg} / \mathrm{m}^{2}\right)$. A blood sample of all participants was collected for assessment of lipid profile, and all underwent an EKG and carotid ultrasound.

BP measurement was according to the guidelines of the Joint National Committee-Seventh Report (JNC VII) (2003). Resting BP was measured three times during the consultation, with an interval of at least 5 minutes between measurements and with the patient in a sitting position, and the average of the two last readings that was recorded. Fasting laboratory tests used standard serum enzymatic assays in a clinical laboratory whose procedures have validated by Brazilian Society of Clinical Pathology. The blood samples were collected in the morning until 8:30 AM, after a 10 to 12-hour fasting, to measure glycosylated hemoglobin, total cholesterol (TC), and triglycerides (TG). The high density lipoprotein cholesterol (HDL-c) was assessed by lipoprotein precipitation, whereas LDL-c was calculated according to
Friedwald's formula (Friedwald et al 1972): LDL-c $=$ TC (HDL-c + TG/5). The reference values were CT lower than $200 \mathrm{mg} / \mathrm{dL}$, LDL-c lower than $130 \mathrm{mg} / \mathrm{dL}$, and HDL-c of 40 $\mathrm{mg} / \mathrm{dL}$ or above, for the control groups, as indicated by the III Brazilian Consensus of Dyslipidemia (2001), and values of CT of $200 \mathrm{mg} / \mathrm{dL}$ or above, LDL-c of $130 \mathrm{mg} / \mathrm{dL}$ or above, and HDL-c lower than $40 \mathrm{mg} / \mathrm{dL}$ for groups III and IV. For glucose levels, the new criteria of the American Diabetes Association (ADA) (2003) for the diagnosis of DM were considered. The ultrasound examinations were obtained with an echocardiograph model Apogee 800 plus, proper to study vessels, with a 32-second scroll system for mode-M and Doppler. For the tests, a multi-frequency transducer ranging from 5 to $8 \mathrm{MHz}$ was used. The investigation of the arteries was guided by the ultrasound rays, which hit the vessel wall perpendicularly, forming a typical 2-line image separated by an anechoic space, allowing the identification of anterior and posterior wall structures. These lines are limited by the blood-intima and media-adventitia interfaces. The distance between these two lines is the intima-media thickness of the vascular wall (Baldassarre et al 1996; Sidhu and Desai 1996; Smilde et al 1997; ASE 2006). All examinations were carried out by the same operator (Smilde et al 1997).

IMT measurement was performed in the distal portion of the right carotid artery (RCA) and left carotid artery (LCA), $1 \mathrm{~cm}$ away from the bifurcation, on the deepest wall, from longitudinal cuts to have a better view of the vessels and their walls (ASE 2006), which allowed identification of 
marked angles and sinuousities. The presence of plaques was investigated throughout left and right carotid arteries, bulb, and internal (IB) and external (EB) branches. The carotid wall with a intima-media thickness of less than $1 \mathrm{~mm}$, ascertained by echocardiogram performed according to the described methodology, was considered normal. IMT was considered for values between $1 \mathrm{~mm}$ and $1.99 \mathrm{~mm}$. The presence of plaque was identified by a well-defined area with IMT 50\% bigger, reaching at least $2 \mathrm{~mm}$, when compared to surrounding areas that could be clearly viewed (Suurkula et al 1994; Millio et al 2006).

\section{Results}

\section{Comparison of the investigated variables between groups I and II}

Table 2 presents the means \pm standard deviation of the continuous variables investigated in groups I and II. Mean SBP readings presented statistically significant differences between the control groups. Mean DBP was higher for group II versus group I, which was also statistically significant. Lipid assessment was also significantly different in the comparison of the means of all variables examined, higher for group II versus group I. IMT-RCA assessment showed a higher mean value for group II versus group I, a statistically significant difference. Mean IMT-LCA value was higher also in group II. Table 3 presents the categorical variables for groups I and II analyzed through the Chi-square test $\left(\chi^{2}\right)$. Analyzing the prevalence of abnormal IMT-RCA values, it was observed a statistically significant difference $\left(\chi^{2}=12.0000\right.$, $p=0.0005)$. Abnormal IMT-LCA was found in a statistically significant difference $\left(\chi^{2}=15.0000, p=0.0001\right)$.
When both carotid arteries were analyzed (left and/or right) a statistically significant difference was observed $\left(\chi^{2}=21.8200, p<0.0001\right)$ (Table 3).

\section{Overall features of the groups of elderly}

Table 4 presents the means \pm standard deviation of the continuous variables analyzed of groups II, III and IV, thus including all elderly subjects of this investigation. Comparison of the means of the variables of normal distribution was made through a Variance Analysis test (F). For discrepant variances, and for variables with not normal distribution, comparison among the groups was made through the KruskalWallis test $(\mathrm{H})$. Analysis of the means of cholesterol levels showed statistically significant difference $(\mathrm{H}=49.6187$, $p<0.0001$ ) when comparing the 3 groups. Comparing the groups 2 by 2 , the mean of group IV $(247.00 \pm 41.73 \mathrm{mg} / \mathrm{dL})$ was significantly higher than of group II (186.80 \pm 16.91 $\mathrm{mg} / \mathrm{dL})$ and of group III (176.93 $\pm 20.53 \mathrm{mg} / \mathrm{dL})$; the mean of group II, however, was similar to the one of group III. Comparing the means of LDL-c, the difference among the 3 groups is significant $(\mathrm{H}=56.6229, p<0.0001)$. The mean of group IV $(167.02 \pm 36.00 \mathrm{mg} / \mathrm{dL})$ was significantly higher when compared to the means of group III $(101.23 \pm 21.08$ $\mathrm{mg} / \mathrm{dL})$ and group II $(108.54 \pm 19.12 \mathrm{mg} / \mathrm{dL})$, but the means of these two groups, II and III, are similar. Comparison of the HDL-c mean values among the 3 groups showed statistical significance $(\mathrm{H}=7.8216, p=0.02)$, being the mean of group II $(54.12 \pm 15.18 \mathrm{mg} / \mathrm{dL})$ higher than the mean of groups III $(49.01 \pm 7.84 \mathrm{mg} / \mathrm{dL})$ and IV (45.31 $\pm 12.21 \mathrm{mg} / \mathrm{dL})$, which had similar mean figures. As for triglycerides, the mean value of group IV $(173.38 \pm 78.71 \mathrm{mg} / \mathrm{dL})$ was higher than the means of groups III $(133.57 \pm 45.01 \mathrm{mg} / \mathrm{dL})$ and II

Table 2 Comparative analysis of controls groups

\begin{tabular}{|c|c|c|c|c|}
\hline Variable & Group I & Group II & Statistic test & $p$ \\
\hline Age & $24.70 \pm 4.16$ & $71.77 \pm 8.65$ & $U=0.0$ & $<0.000$ I \\
\hline Weight & $64.50 \pm 9.14$ & $65.00 \pm|1.5|$ & $t=0.18$ & 0.862 \\
\hline Height & $1.69 \pm 0.09$ & $1.61 \pm 0.08$ & $\mathrm{t}=3.80$ & $<0.00$ I \\
\hline BMI & $22.63 \pm 3.01$ & $25.11 \pm 3.72$ & $\mathrm{t}=2.85$ & 0.006 \\
\hline SBP & $114.63 \pm 7.49$ & $125.17 \pm 9.19$ & $\mathrm{t}=4.87$ & $<0.001$ \\
\hline DBP & $71.73 \pm 5.49$ & $75.63 \pm 6.51$ & $\mathrm{t}=2.5 \mathrm{I}$ & 0.020 \\
\hline Cholesterol & $159.80 \pm 24.02$ & $187.10 \pm 15.72$ & $U=160.0$ & $<0.00$ I \\
\hline LDL-c & $97.00 \pm 18.20$ & $108.54 \pm 19.12$ & $\mathrm{t}=2.39$ & 0.020 \\
\hline HDL-c & $45.90 \pm 13.08$ & $54.11 \pm 15.18$ & $\mathrm{t}=2.25$ & 0.028 \\
\hline TG & $84.43 \pm 35.04$ & $123.73 \pm 54.30$ & $U=254.5$ & 0.004 \\
\hline Glucose & $87.80 \pm 11.42$ & $91.83 \pm 13.00$ & $\mathrm{t}=1.28$ & 0.206 \\
\hline IMT-RCA & $0.61 \pm 0.10$ & $0.95 \pm 0.20$ & $U=32.5$ & 0.001 \\
\hline IMT-LCA & $0.55 \pm 0.10$ & $0.97 \pm 0.22$ & $U=15.5$ & $<0.00 \mathrm{I}$ \\
\hline
\end{tabular}

Abbreviations: BMI, body mass index; LDL-c, low density lipoprotein cholesterol; HDL-c, high density lipoprotein;TG, triglycerides; SBP, systolic blood pressure; DBP, diastolic blood pressure; IMT-RCA, intima-media thickening right carotid artery; IMT-LCA, intima-media thickening left carotid artery. 
Table 3 Distribution of analyzed continuous variables in controlgroups

\begin{tabular}{lllll}
\hline Variable & Group I & Group II & Statistic test $\chi^{2}$ & $\mathbf{p}$ \\
\hline Gender $(\mathrm{M} / \mathrm{F})$ & $19 / \mathrm{II}$ & $9 / 2 \mathrm{I}$ & 6.7000 & 0.0100 \\
Overweight $(\mathrm{Y} / \mathrm{N})$ & $6 / 24$ & $15 / 15$ & 6.0000 & 0.1490 \\
IMT-RCA $(\mathrm{Y} / \mathrm{N})$ & $0 / 30$ & $10 / 20$ & 12.0000 & 0.0005 \\
IMT-LCA $(\mathrm{Y} / \mathrm{N})$ & $0 / 30$ & $12 / 18$ & 15.0000 & $0.000 \mathrm{I}$ \\
IMT-RLCA $(\mathrm{Y} / \mathrm{N})$ & $0 / 30$ & $16 / 14$ & 21.8200 & $<0.000$ I \\
PlaqueR $(\mathrm{Y} / \mathrm{N})$ & $0 / 30$ & $4 / 26$ & 4.2857 & 0.0562 \\
PlaqueL $(\mathrm{Y} / \mathrm{N})$ & $0 / 30$ & $4 / 26$ & 4.2857 & 0.0600 \\
PlaqueRL $(\mathrm{Y} / \mathrm{N})$ & $0 / 30$ & $5 / 25$ & 5.5000 & 0.0522 \\
\hline
\end{tabular}

Abbreviations: Y, yes; N, no; M, male; F, female; IMT-RCA, intima-media thickening right carotid artery; IMT-LCA, intima-media thickening left carotid artery; IMT-RLCA, intima media thickening right or left carotid artery; PlaqueR, plaque in right carotid; PlaqueL, plaque in left carotid; PlaqueRL, plaque in right or left carotid.

$(123.73 \pm 54.27 \mathrm{mg} / \mathrm{dL})$, which did not present a significant difference.

SBP means were similar for groups III and IV, and both were significantly higher than for group II ( $\mathrm{F}=72.5561$, $p=0.0001)$. The mean for group III was $166.63 \pm 16.08$ $\mathrm{mmHg}$, and for group IV, $166.80 \pm 20.07 \mathrm{mmHg}$, whereas for group II it was $125.17 \pm 9.19 \mathrm{mmHg}$. DBP assessment showed higher and similar mean values for groups III (83.30 \pm $4.81 \mathrm{mmHg})$ and IV $(84.08 \pm 3.30 \mathrm{mmHg})$. When compared to group II $(75.63 \pm 6.51 \mathrm{mmHg})$, there was a significant statistical difference $(\mathrm{H}=33.5633, p=0.0001)$. In terms of pulse pressure, comparison among the 3 groups evidenced a statistically significant difference $(p=0.0001)$, with III and IV presenting means higher than II $(49.53 \pm 8.61 \mathrm{mmHg})$, but similar one to the other $(82.33 \pm 16.5 \mathrm{mmHg}$ and $84.72 \pm$ $18.51 \mathrm{mmHg}$ respectively). Comparison of the IMT-RCA among the 3 groups showed statistically significant difference
$(\mathrm{F}=4.1861, p=0.0181)$. The mean of group III was higher than of the other groups $(1.10 \pm 0.24 \mathrm{~mm})$, and the mean of group II $(0.95 \pm 0.20 \mathrm{~mm})$ was similar to the one of group IV $(1.00 \pm 0.18 \mathrm{~mm})$. The analysis of IMT-LCA mean values did not reveal statistically significant difference $(\mathrm{F}=1.7432$, $p=0.1805$ ). The mean of group II was of $0.97 \pm 0.22 \mathrm{~mm}$; group III, $1.07 \pm 0.27$; and group IV, $1.05 \pm 0.22 \mathrm{~mm}$.

\section{Distribution of the categorical variables assessed in the groups of elderly}

The categorical variables examined in groups II, III and IV are presented in Table 5. In the comparison among groups, a statistically significant difference was observed regarding the use of medication among the 3 groups $\left(\chi^{2}=99.0000\right.$, $p<0.0001)$. In groups III and IV, all subjects $(100 \%)$ used a medication, whereas in group II, none of them did $(0 \%)$. For the presence of PlaqueR, there was significant difference in the comparison among the 3 groups $\left(\chi^{2}=6.6194\right.$, $p=0.0365)$. The presence of PlaqueL was also statistically significant $\left(\chi^{2}=6.6558, p=0.0358\right)$ among the groups. The presence of plaque in the RLCA had also a statistically significant distribution among the 3 groups $\left(\chi^{2}=10.0839\right.$, $p=0.0065)$. When comparing distribution of IMT-RCA among the 3 groups, it was seen at a lower prevalence in the group of healthy elderly compared to the other groups, with the difference being statistically significant $\left(\chi^{2}=11.4265\right.$, $p=0.0033)$. Regarding the presence of IMT-LCA, there was no significant difference among the 3 groups $\left(\chi^{2}=5.4892\right.$, $p=0.0643)$. Similarly, there was no statistically significant difference in the distribution of IMT-RLCA among the 3 groups $\left(\chi^{2}=5.2484, p=0.0725\right)$.

Table 4 Baseline characteristics of studied elderly groups

\begin{tabular}{|c|c|c|c|c|c|c|}
\hline Variable & Group II & Group III & Group IV & Statistic test & Value de $p$ & Comparison 2 a 2 \\
\hline Age & $71.77 \pm 8.64$ & $71.20 \pm 7.16$ & $70.03 \pm 7.15$ & $\mathrm{~F}=0.4720$ & 0.6252 & \\
\hline Weight & $64.96 \pm 11.52$ & $64.45 \pm 11.01$ & $70.01 \pm 12.30$ & $F=2.3290$ & 0.1032 & \\
\hline Height & $1.61 \pm 0.08$ & $1.61 \pm 0.10$ & $1.6 \mathrm{I} \pm 0.08$ & $F=0.0188$ & 0.9814 & \\
\hline BMI & $25.11 \pm 3.72$ & $25.09 \pm 3.34$ & $27.17 \pm 4.90$ & $F=2.9600$ & 0.0566 & \\
\hline Cholesterol & $|86.80 \pm| 6.9 \mid$ & $176.93 \pm 20.53$ & $247.00 \pm 41.73$ & $H=49.6187$ & $<0.0001$ & $\overline{4>3=2}$ \\
\hline LDL-c & $108.54 \pm 19.12$ & $101.23 \pm 21.08$ & $167.02 \pm 36.00$ & $H=56.6229$ & $<0.0001$ & $4>3=2$ \\
\hline HDL-c & $54.12 \pm 15.18$ & $49.01 \pm 7.84$ & $45.31 \pm 12.21$ & $H=7.8216$ & 0.0200 & $2>4=3$ \\
\hline TG & $123.73 \pm 54.27$ & $133.57 \pm 45.0 \mid$ & $|73.38 \pm 78.7|$ & $H=9.4884$ & 0.0087 & $4>3=2$ \\
\hline Glucose & $91.83 \pm 12.96$ & $90.00 \pm 11.50$ & $96.62 \pm 13.90$ & $F=2.2825$ & 0.1078 & \\
\hline SBP & $125.17 \pm 9.19$ & $166.63 \pm 16.08$ & $166.80 \pm 20.07$ & $F=72.556 \mathrm{I}$ & 0.0001 & $4=3>2$ \\
\hline DBP & $75.63 \pm 6.51$ & $83.30 \pm 4.81$ & $84.08 \pm 3.30$ & $\mathrm{H}=33.5633$ & 0.0001 & $4=3>2$ \\
\hline PULSEP & $49.53 \pm 8.61$ & $82.33 \pm 16.5$ & $84.72 \pm|8.5|$ & $H=50.9636$ & 0.0001 & $4=3>2$ \\
\hline IMT-RCC & $0.95 \pm 0.20$ & $1.10 \pm 0.24$ & $1.00 \pm 0.18$ & $F=4.186 I$ & 0.0181 & $3>2=4$ \\
\hline IMT-LCCA & $0.97 \pm 0.22$ & $1.07 \pm 0.27$ & $1.05 \pm 0.22$ & $\mathrm{~F}=\mathrm{I} .7432$ & 0.1805 & 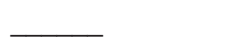 \\
\hline
\end{tabular}

Abbreviations: BMI, body mass index; LDL-c, low density lipoprotein cholesterol;HDL-c, high density lipoprotein;TG, triglycerides; SBP, systolic blood pressure; DBP, diastolic blood pressure; PULSEP, pulse pressure; IMT-RCC, intima-media thickening common right common carotid; IMT-LCCA, intima-media thickening common left common carotid. 
Table 5 Distribution of categorical variables in groups II, III e IV

\begin{tabular}{llllll}
\hline Variable & Group II & Group III & Group IV & Statistic test $\chi^{2}$ & $\boldsymbol{p}$ \\
\hline Gender $(\mathrm{M} / \mathrm{F})$ & $9 / 21$ & $12 / 18$ & $15 / 24$ & 0.7706 & 0.6803 \\
Overweight $(\mathrm{Y} / \mathrm{N})$ & $15 / 15$ & $19 / 1 \mathrm{I}$ & $25 / 14$ & 1.6502 & 0.4382 \\
Drugs $(\mathrm{Y} / \mathrm{N})$ & $0 / 30$ & $30 / 0$ & $39 / 0$ & 99.0000 & $<0.000 \mathrm{I}$ \\
PlaqueR $(\mathrm{Y} / \mathrm{N})$ & $4 / 26$ & $11 / 19$ & $16 / 23$ & 6.6194 & 0.0365 \\
PlaqueL $(\mathrm{Y} / \mathrm{N})$ & $4 / 26$ & $13 / 17$ & $11 / 28$ & 6.6558 & 0.0358 \\
PlaqueRL $(\mathrm{Y} / \mathrm{N})$ & $5 / 25$ & $15 / 15$ & $20 / 19$ & 10.0839 & 0.0065 \\
IMT-RCA $(\mathrm{Y} / \mathrm{N})$ & $10 / 20$ & $23 / 7$ & $22 / 17$ & 11.4265 & 0.0033 \\
IMT-LCA $(\mathrm{Y} / \mathrm{N})$ & $12 / 18$ & $20 / 10$ & $25 / 14$ & 5.4892 & 0.0643 \\
IMT-RLCA $(\mathrm{Y} / \mathrm{N})$ & $16 / 14$ & $24 / 6$ & $28 / 11$ & 5.2484 & 0.0725 \\
\hline
\end{tabular}

Abbreviations: M, male; F, female; Y, yes; N, no; PlaqueR, right plaque; PlaqueL, left plaque; PlaqueRL, plaque in right and or left carotid; IMT-RCA, intima-media thickening right carotid artery; IMT-LCA, intima-media thickening left carotid artery; IMT-RLCA, intima-media thickening right and/or left carotid artery.

\section{Evaluation of categorical variables regarding $\mathrm{ISH}$}

The assessment of the frequency distribution of the categorical variables examined in relation to ISH is shown in Table 6.

In regards to the presence of dyslipidemia, there was significant difference between the two groups $\left(\chi^{2}=27.9783\right.$, $p<0.00001)$. The distribution of IMT-RCA between the 2 groups was statistically significant $\left(\chi^{2}=8.6087\right.$, $p=0.0034)$. Comparison of IMT-LCA distribution between the 2 groups showed a statistically significant difference $\left(\chi^{2}=5.4435, p=0.0196\right)$. In regards to PlaqueR and to PlaqueL distribution, there was a statistically significant difference between the 2 groups $\left(\chi^{2}=6.4696, p=0.0110\right.$ and $\chi^{2}=4.7426, p=0.0294$, respectively). Comparing the distribution of PlaqueRL between the 2 groups, there was a statistically significant difference $\left(\chi^{2}=10.0724\right.$, $p=0.0040)$.

Table 6 Evaluation of studied continuous categoric variables related to ISH

\begin{tabular}{lllll}
\hline Variable & $\begin{array}{l}\text { Without } \\
\text { ISH }\end{array}$ & $\begin{array}{l}\text { With } \\
\text { ISH }\end{array}$ & $\begin{array}{l}\text { Statistic } \\
\text { test } \boldsymbol{\chi}^{2}\end{array}$ & $\boldsymbol{p}$ \\
\hline Gender $(\mathrm{M} / \mathrm{F})$ & $9 / 2 \mathrm{I}$ & $27 / 42$ & 0.7533 & 0.3855 \\
Dyslip $(\mathrm{S} / \mathrm{N})$ & $0 / 30$ & $39 / 30$ & 27.9783 & 0.0000 I \\
Overweight $(\mathrm{Y} / \mathrm{N})$ & $15 / 15$ & $44 / 25$ & $1.646 \mathrm{I}$ & 0.1995 \\
IMT-RCA $(\mathrm{Y} / \mathrm{N})$ & $10 / 20$ & $45 / 24$ & 8.6087 & 0.0034 \\
IMT-LCA $(\mathrm{Y} / \mathrm{N})$ & $12 / 18$ & $45 / 24$ & 5.4435 & 0.0196 \\
IMT-RLCA $(\mathrm{Y} / \mathrm{N})$ & $16 / 14$ & $52 / 17$ & 4.7176 & 0.0299 \\
PlaqueR $(\mathrm{Y} / \mathrm{N})$ & $4 / 26$ & $27 / 42$ & 6.4696 & 0.0110 \\
PlaqueL $(\mathrm{Y} / \mathrm{N})$ & $4 / 26$ & $24 / 45$ & 4.7426 & 0.0294 \\
PlaqueRL $(\mathrm{Y} / \mathrm{N})$ & $5 / 25$ & $35 / 34$ & 10.0724 & 0.0040 \\
\hline
\end{tabular}

Abbreviations: ISH, isolated systolic hypertension; $\mathrm{M}$, male; $\mathrm{F}$, female; Y, yes; $\mathrm{N}$, no; Dyslip, dyslipidemia; IMT-RCA, intima-media thickening right carotid artery; IMT-LCA, intima-media thickening left carotid artery; IMT-RLCA, intima-media thickening right and/or left carotid artery; PlaqueR, right plaque; PlaqueL, left plaque; PlaqueRL, plaque in right and or left carotid.

\section{Evaluation of the categorical variables regarding dyslipidemia}

Distribution of the categorical variables in regards to dyslipidemia is presented in Table 7. The distribution of ISH between the dyslipidemia-free and dyslipidemia groups had a statistically significant difference $\left(\chi^{2}=27.9783, p<0.0001\right)$. When the use of medication was compared between the dyslipidemia and the dyslipidemia-free groups, a statistically significant difference was observed $\left(\chi^{2}=27.9783\right.$, $p<0.0001)$. The presence of IMT and Plaque in the 2 groups had no statistically significant difference of distribution.

\section{Odds ratio for the presence of IMT in ISH}

Odds ratio was calculated to assess the likelihood of IMT when ISH was present. Table 8 presents the odds ratio for IMT of the carotid arteries in ISH cases. The odds ratio for the presence of IMT-RCA in ISH cases was of 1.9167. The relative risk for IMT-RCA was of 3.75 times considering the absence of ISH/presence of ISH ratio $\left(\chi^{2}=8.6671\right.$, $p=0.0032)$. For the presence of IMT-LCA in ISH cases, the odds ratio was 1.7250 . The relative risk for IMT-LCA was 2.81 times, considering the absence of ISH/presence of ISH ratio $\left(\chi^{2}=5.4204, p=0.0199\right)$. The odds ratio for IMT-RLCA in ISH cases was of 1.8941. The relative risk for IMT-RLCA was 2.67 times, considering the absence of ISH/presence of ISH ratio $\left(\chi^{2}=4.5700, p=0.0325\right)$.

Table 9 presents the odds ratio in ISH cases for occurrence of plaques in the carotid arteries. Odds ratio was used to calculate the likelihood of occurring plaques in carotid arteries of ISH patients. The odds ratio for the presence of PlaqueR in ISH patients was 1.4238. The relative risk for occurrence of PlaqueR was 4.18 times, considering the absence of ISH/presence of ISH ratio $\left(\chi^{2}=7.1458, p=0.0075\right)$. In regards to ISH, the odds ratio for occurence of PlaqueL was 1.3289. The relative risk for PlaqueL was 3.47 times, considering the absence 
Table 7 Evaluation of continuous categoric variables studied related to dyslipidemia

\begin{tabular}{lllll}
\hline Variable & Without dyslipidemia & With dyslipidemia & Statistic test $\chi^{2}$ & $p$ \\
\hline Gender $($ M F $)$ & $21 / 39$ & $15 / 24$ & 0.1224 & 0.7265 \\
ISH $(\mathrm{Y} / \mathrm{N})$ & $30 / 30$ & $39 / 0$ & 27.9783 & $<0.000 \mathrm{I}$ \\
Drugs $(\mathrm{Y} / \mathrm{N})$ & $30 / 30$ & $39 / 0$ & 27.9783 & $0.000 \mathrm{I}$ \\
MT-RCA $(\mathrm{Y} / \mathrm{N})$ & $33 / 27$ & $22 / 17$ & 0.0190 & 0.8903 \\
IMT-LCA $(\mathrm{Y} / \mathrm{N})$ & $32 / 28$ & $25 / 14$ & 1.1223 & 0.2894 \\
IMT-RLCA (Y/N) & $20 / 40$ & $11 / 28$ & 0.2890 & 0.5909 \\
PlaqueR $(\mathrm{Y} / \mathrm{N})$ & $15 / 45$ & $16 / 23$ & 2.8223 & 0.0930 \\
PlaqueL $(\mathrm{Y} / \mathrm{N})$ & $17 / 43$ & $11 / 28$ & 0.0020 & 0.9890 \\
PlaqueRL $(\mathrm{Y} / \mathrm{N})$ & $20 / 40$ & $20 / 19$ & 3.1623 & 0.0753 \\
\hline
\end{tabular}

Abbreviations: M, male; F, female; Y, yes; N, no; ISH, isolated systolic hypertension; IMT-RCA, intima-media thickening right carotid artery; IMT-LCA, intima-media thickening left carotid artery; IMT-RLCA, intima-media thickening right and/or left carotid artery; PlaqueR, right plaque; PlaqueL, left plaque; PlaqueRL, plaque in right and or left carotid.

of ISH/presence of ISH ratio $\left(\chi^{2}=5.2088, p=0.0225\right)$. The odds ratio for PlaqueRL in ISH patients was 1.6912. The relative risk for PlaqueRL was 5.15 times, considering the absence of ISH/presence of ISH ratio $\left(\chi^{2}=10.9001, p=0.001\right)$.

\section{Discussion}

In the first stage of this investigation, groups I and II, which included, respectively, younger and healthy elderly subjects (Table 2) were compared. The purpose was to identify the main differences between the 2 groups in order to establish the normal parameters for the healthy elders.

Many authors (La Rosa 1996; Sega et al 1997) have found higher mean SBP and DBP values in healthy elders when compared with healthy younger subjects. Sega and colleagues (1997) randomized a sample of 800 subjects, stratifying by gender and age ( 65 to 74 years). BP was measured at 3 different points, and the mean values were compared to the mean values previously established in a younger population. After statistical calculations, higher mean BP values were found for the group of elderly subjects. In this study, similar results were found, with mean values significantly higher for both SBP $(p<0.001)$ and DBP $(p=0.020)$ for group II versus group I.

When the mean values for lipids were analyzed in the 2 groups, total cholesterol, LDL-c and TG were significantly higher in group II versus group I, and these are unanimously accepted risk factors for CVD. However, also the mean HDL-c values were higher for the group of elderly, and this was statistically significant ( $p=0.028$ ) versus the group of younger people, and this is a protective factor for the development of CVD. These results were similar to those of other studies, such as La Rosa's (1996), in which there was observed an increase in the levels of total cholesterol, LDL-c, TG, and HDL-c with age.

In regards to the IMT for both RLCA, comparison of the means between the 2 groups was statistically significant at $p=0.001$ and $p<0.001$, respectively. In our investigation, it was observed that aging contributes to IMT of the carotid arteries. Garcia and colleagues (1996) have associated both IMT and presence of plaque, to aging. Hughes and associates (1995) observed and association between IMT and aging, even in normotensive subjects. However, Fabris and colleagues (1994), in spite of having related IMT to aging, observed that this did not occur in very old subjects, and raised the possibility of $\mathrm{RF}$, except for high $\mathrm{BP}$, playing a less important role after the age of 75. Comparison between groups I and II has, therefore, shown an association between IMT and aging. A number of studies (Suurkula et al 1994, 1996; Bonithon-Kopp et al 1996; O’Leary et al 1996; Howard et al 1997; Wilt et al 1997; Millio et al 2006; Wang et al 2006; ) have been carried out with the purpose of investigating IMT and/or the presence of plaques in connection with risk factors and CVDs. An increase of the IMT or a detection of protuberance in the vascular lumen have both been reported as ultrasound markers of atherosclerosis. The development of high-resolution ultrasound imaging, such as the echo-Doppler, has allowed the recording of echoes of the arterial wall, such as the carotid arteries (ASE 2006; Asrafian et al 2007). The reliability of the carotid arteries IMT ultrasound images has been extensively examined (Joakimsem 1997; Sidhu and Desai 1997; Smilde et al 1997; ASE 2006; Asrafian et al 2007). Sidhu and Desai (1997) demonstrated the reliability of the method by measuring the distal wall of common artery, always on a longitudinal plan $1 \mathrm{~cm}$ away from the bulb. Comparison among the 3 groups allowed the authors to conclude that theirs was an accurate and reliable method to assess IMT of the carotid arteries. Smilde and colleagues (1997) examined carotid and femoral arteries using a similar methodology, and concluded that the measurement of IMT is reliable, even if IMT is present. The IMT mean values in their investigation were similar to those of population 
Table 8 ISH and odds ratio for IMT

\begin{tabular}{|c|c|c|c|c|c|}
\hline & Odds & Cl $95 \%$ & $\begin{array}{l}\text { Relative risk } \\
\text { HSI no/HSI yes }\end{array}$ & $\chi^{2}$ & $p$ \\
\hline IMT-RCA & 1.9167 & $1.27 \mid 5-2.8892$ & 3.75 & 8.6671 & 0.0032 \\
\hline IMT-LCA & 1.7250 & I.II59-2.6667 & 2.81 & 5.4204 & 0.0199 \\
\hline IMT-RLCA & I.894| & $1.0790-3.3250$ & 2.67 & 4.5700 & 0.0325 \\
\hline
\end{tabular}

Abbreviations: Odds, odds ratio; $\mathrm{Cl}$, confidence interval; $\mathrm{ISH}$, isolated systolic hypertension; $\chi^{2}$, chi-square; $p$, standard deviation; IMT-RCA, intima-media thickening right carotid artery; IMT-LCA, intima-media thickening left carotid artery; IMT-RLCA, intima-media thickening right and/or left carotid artery.

studies, such as the Atherosclerosis Risk in Communities (ARIC) (Howard et al 1997), the Vascular Aging Study (EVA) (Bonithon-Kopp et al 1996), and the Risk Intervention Study Group (RIS) (Suurkula et al 1994), among others. The means found in our study match these values.

The setting of a group of healthy elders (group II) has allowed comparison between this control group with group III, of ISH elders, and group IV, of elders with ISH and dyslipidemia, in order to assess the importance of aging, of anthropometric indices, of ISH and of dyslipidemia in IMT (Table 4).

As for the presence of IMT-RCA (Table 5), there was statistically significant difference among groups II, III and IV $(p=0.0033)$, with higher values for groups III and IV. However, when IMT-LCA and IMT-RLCA were analyzed, in spite of higher values for groups III and IV, they did not reach statistical significance, with $p=0.0643$ and $p=0.0725$, respectively.

The possible antiatherosclerotic action of antihypertensive agents, regardless of their hypotensive effects, has been focused by a number of works. Measurement of carotid arteries IMT was used as a parameter to assess the process of atherosclerosis (Bonithon-Kopp et al 1996; Wang et al 2006; Girerd et al 1998; Zanchetti 1996), which leads to a initial conclusion that ACEIs and calcium channels antagonists would be effective in reducing IMT. Based on these results, this investigation standardized the antihypertensive agents used by the patients, over concern on their influence over IMT. For the same reason, patients using lipid-lowering drugs were excluded (Salonem et al 1995; Baldassare et al 1996; Hodis et al 1996; Spacil et al 1997).

Presence of plaque was analyzed in the 3 groups (Table 5), and significant difference was found, with lower prevalence in group II for PlaqueR $(p=0.0365)$, PlaqueL $(p=0.0358)$ and PlaqueRL $(p=0.0065)$.

The results from the comparison of groups II, III and IV (Table 5) lead to the conclusion that, in groups III and IV, there was a positive association between ISH and/or dyslipidemia and IMT-RCA and presence of PlaqueR, PlaqueL and PlaqueRL. However, it was through the comparison between subjects without and with ISH, and those without and with dyslipidemia, that one could establish the association between ISH and dyslipidemia in regards to IMT and presence of plaque.

A number of works (Van Merode et al 1993; Suurkula et al 1994; Wilson et al 1994; Hughes et al 1995; BonithonKopp et al 1996; Panza 1997) in hypertensive subjects, using carotid ultrasound imaging to measure the IMT, have found a positive relationship between high BP, IMT and presence of plaques in the carotid arteries. O'Leary and colleagues (1996) found a strong association between ISH and IMT in the population they investigated. In our study, the results from the comparison between elderly with ISH and normotensive elderly subjects were in accordance with the reviewed literature (Table 6). Assessment of the IMT revealed higher values for the hypertensive group, of statistical significance for all, IMT-RCA ( $p=0.0034)$, IMT-LCA $(p=0.0196)$ and IMT-RLCA $(p=0.0299)$. The relative risk for the presence of IMT, considering the absence of ISH/ presence of ISH ratio, was of 3.75 for IMT-RCA; 2.81 for IMT-LCA; and 2.67 for IMT-RLCA (Table 8). Similarly, comparison between elders with and without in regards to the presence of plaques also showed significantly higher values for the hypertensive group for Plaque $\mathrm{R}(p=0.0110)$, PlaqueL ( $p=0.0294)$ and PlaqueRL $(p=0.0040)$ (Table 6$)$. Considering the absence of ISH/presence of ISH ratio, the relative risk was 4.18 for PlaqueR, 3.47 for PlaqueL, and 5.15 for PlaqueRE. These results evidenced the positive association between ISH and presence of IMT and presence of plaques in carotid arteries (Table 9).

In regards to dyslipidemia, observation studies in elderly populations have showed contradictory results. O'Leary and colleagues (1996) investigated a population of 5117 subjects with 65 years or older, and found a positive relation between high levels of LDL-c and IMT, while high levels of HDL-c presented a negative relationship. Bonithon-Kopp and associates (1996) observed a positive relationship

Table $9 \mathrm{ISH}$ and odds ratio for plaque

\begin{tabular}{llllll}
\hline & Odds & IC 95\% & $\begin{array}{l}\text { Relative risk } \\
\text { HSI no/HSI yes }\end{array}$ & $\chi^{2}$ & $p$ \\
\hline PlacaR & 1.4238 & $1.1250-1.8020$ & 4.18 & 7.1458 & 0.0075 \\
PlacaL & 1.3289 & $1.064 I-1.6596$ & 3.47 & 5.2088 & 0.0225 \\
PlacaRL & 1.6912 & $1.2680-2.2555$ & 5.15 & $10.900 \mathrm{I}$ & 0.001 \\
\hline
\end{tabular}

Abbreviations: ISH, isolated systolic hypertension; Odds, odds ratio; $\mathrm{Cl}$, confidence interval; ISH, isolated systolic hypertension; $\chi^{2}$, chi-square; $p$, standard deviation; PlaqueR, right plaque; PlaqueL, left plaque; PlaqueRL, plaque in right and or left carotid. 
between cholesterol levels and presence of plaques in the carotid arteries; however, no relationship was found for IMT. Surkula and colleagues (1994) in the Multiple Risk Intervention in High-Risk Hypertensive Patients study did not find a positive relationship between high cholesterol levels and IMT in an elderly population. In our work, we did not find a positive relationship between dyslipidemia and IMT, and it was not a risk variable for the presence of plaque. PlaqueRL did have a marginal statistic value $(p=0.0753)$ (Table 7), but these results are probably not statistically relevant due to the small number of the sample subjects $(n=39)$.

\section{Conclusion}

In this investigation, it was evidenced that the measurement of the intima-media thickness through ultrasound imaging, a noninvasive, low-cost, easy-to-perform method, was valid to assess IMT of carotid arteries in elderly subjects. The results showed aging to be an independent factor positively related to IMT. It was also possible to demonstrate that ISH was a RF of IMT of the RCA ( $p=0.0034)$, IMT of the LCA $(p=0.0196)$, and IMT of the RCA and/or LCA $(p=0.0299)$, as well as a RF for the development of plaque in RCA $(p=0.110)$, plaque in the LCA $(p=0.294)$, and plaque in RCA and/or LCA $(p=0.040)$. However, to ascertain the role of dyslipidemia in the development of IMT and of plaques in carotid arteries of elderly subjects, we believe it is necessary a longitudinal follow-up of the studied population, to establish, once and for all, as it already happens with ISH, the importance of management and treatment of dyslipidemia in elders.

\section{References}

American Diabetes Association. 2003. Report of the Expert Committee on the Diagnosis and Classification of Diabetes Mellitus. Diabet Care, 26:5-20.

American Heart Association. 2007. Heart Disease and Stroke Statistics 2007 Update. Circulation. 115:69-171.

American Society of Echocardiography (ASE). 2006. Clinical application of noninvasive vascular ultrasound in cardiovascular risk stratification: a report from the American Society of Echocardiography and the Society of Vascular Medicine and Biology. J Am Soc Echocardiogr, 19:943-54

Baldassarre D, Tremoli E, Francheschini G, et al. 1996. Plasma lipoprotein(a) is an independent factor associated with carotid wall thickening in severely but not moderately hyperchosterolemic patients. Stroke, 27:1044-9.

Bilato C, Crow MT. 1996. Atherosclerosis and the vascular biology of aging. Aging, 8:222-4.

Bonithon-Kopp C, Touboul PJ, Berr C, et al. 1996. Relation of intima-media thickness to atherosclerosis plaques in carotid arteries. The Vascular Aging (EVA) Study. Artheriocler Thromb Vasc Biol, 16:310-16.

Cutler JA. 1996. High blood pressure and end organ damage. J Hypertension, 14:3-6.
Davidson MH, Kurlandski SB, Kleinpell RM, et al. 2003. Lipid management in the elderly. Prev Cardiol, 6:128-33.

Endemann DH, Schiffrin EL. 2004. Endothelial dysfunction. J Am Soc Nephrol, 15:1983-92.

Fabris F, Zanocchi M, Bo M, et al. 1994. Carotid plaque, aging and risk factors. A study of 457 subjects. Stroke, 25:113-40.

Fletcher GF, Bufalino V, Costa F, et al. 2007 Efficacy of drug therapy in the secondary prevention of cardiovascular disease and stroke. Am J Cardio, 99:1-35.

Friedwald WT, Levy I, Fredrickson DS. 1972. Estimation of the concentration of low-density lipoprotein cholesterol in plasma, without use of the preparative ultracentrifuge. Clin Chem, 18:499-502.

Millio G, Corrado E, Sorrentino D, et al. 2006. Asymptomatic carotid lesions and aging: role of hypertension and other traditional and emerging risk factors. Arch Med Res, 37:342-7.

Garcia JH, Khang-Loon H. 1996. Carotid atherosclerosis. Definition, pathogenesis, and clinical significance. Neuroimaging Clin $\mathrm{N} \mathrm{Am}$, 6:801-10.

Girerd X, Giannattsio C, Moulin C, et al. 1998. Regression of radial artery wall hypertrophy and improvement of carotid artery compliance after long-term antihypertensive treatment in elderly patients. $\mathrm{J} \mathrm{Am} \mathrm{Coll}$ Cardiol, 31:1064-73.

Hodis HN, Mack WJ, La Breel L, et al. 1996. Reduction in carotid arterial wall thickness using lovastatin and dietary: a randomized controlled clinical trial. Ann Intern Med, 1234:548-56.

Howard G, Manolio TA, Burk GL, et al. 1997. Does the association of risk factors and atherosclerosis change with the age? An analysis of the combined ARIC and CHS cohorts. The Atherosclerosis Risk in Communities (ARIC) and Cardiovascular Health Study (CHS) investigators. Stroke, 28:1693-1701.

Hughes AD, Sinclair AM, Sever PS, et al. 1995. Structural changes in the vascular system of untreated essential hypertension. Blood Press, 4:42-7.

Brazilian Consensus of Dyslipidemia. 2001. III Diretrizes Brasileiras sobre Dislipidemia e Diretriz de Prevenção da Aterosclerose da Sociedade Brasileira e Cardiologia. Arq Brás Cardio, 77:4-48.

Joakimsem O, Bonaa KH, Bugge ES. 1997. Reproducibility of ultrasound assessment of carotid plaque occurrence, thickness and morphology. The Tromso Study. Stroke, 28:2201-07.

Joint National Committee on Prevention, Detection, Evaluation, and Treatment of High Blood Pressure. Seventh annual report. (JNC VII). 2003. Hypertension, 42:1206-52.

Jorge PAR. 1997. Endotélio, lípides e aterosclerose. Arq Bras Cardiol, 68:129-34.

Kalache A, Veras RP, Ramos LR. 1987. O envelhecimento da população mundial. Um desafio novo. Rev Saúde Publ, 21:200-10.

Kannel WB. 1996. Cardiovascular risk factors in the older adult. Hosp Pract, 31:135-48.

La Rosa JC. 1996. Dyslipidemia and coronary artery disease in the elderly. Clin Geriatr Med, 12:33-40.

Lewis M. 1993. Major factors contributing to longevity. In: An INIA workshop on the future of ageing. Valletta: Malta.

Libby P. 2006. Biologia Vascular da Aterosclerose. In: Braunwald Tratado de Doenças Cardiovasculares. 7th ed, Elservier Editora Ltd, p. 921-7.

Luscher TF, Dohi Y, Tanner FC, et al. 1991. Endothelium-dependent control of vascular tone: effects of age, hypertension and lipids. Basic Res Cardiol, 2:143-58.

Luscher TF, Dohi Y, Tschudi MR. 1992. Endothelium-dependent regulation of resistance arteries: alterations with aging and hypertension. J Cardiovasc Pharmacol, 19:34-42.

Noll G, Luscher TF. 1994. Influence of lipoproteins on endothelial function. Thromb Res, 74:45-54.

O’Leary DH, Polak JF, Kronmal RA, et al. 1996. Thickening of the carotid wall: A marker for atherosclerosis in the elderly? Cardiovascular Health Study Collaborative Research Group. Stroke, 27:224-31.

Organização Mundial de Saúde (OMS). 1997. The World Health Report 1997. Genebra, Suiça. 
Panza JA. 1997. Endothelial dysfunction in essential hypertension. Clin Cardiol, 20:26-33.

Salonem R, Nyyssonen K, Porkkala E, et al. 1995. Kuopio Atherosclerosis Prevention Study (KAPS): a population-based primary prevention trial of the effect of LDL lowering on atherosclerotic progression in carotid and femoral arteries. Circulation, 92:1758-64.

Sega R, Cesana G, Milesi C, et al. 1997. Ambulatory and home blood pressure normality in the elderly: data from PAMELA population. Hypertension, 30:1-6.

Sidhu PS, Desai SR. 1997. A simple and reproducible method for assessing intimal-medial thickness of the common carotid artery. Br J Radiol, 70:85-90.

Smilde TJ, Wollersheim H, Van Langen H, et al. 1997. Reproducibilility of ultrasonographic measurements of different carotid and femoral artery segments in healthy subjects and in patients with increased intima-media thickness. Clin Sci, 93:317-24.

Spacil J, Ceska R, Sobra J, et al. 1997. Decreasing common carotid artery intimal thickness during hypolipidemic therapy. Angiology, 48:761-7.

Suurkula M, Agewall S, Fargerberg B, et al. 1994. Ultrasound evaluation of an atherosclerotic manifestation in the carotid artery in high-risk hypertensive patients. Risk Intervention Study (RIS) Group. Arterioscler Thrombo, 14:1297-1304.

Suurkula M, Agewall S, Fargerberg B, et al. 1996. Multiple risk intervention in high-risk hypertensive patients. a 3-year ultrasound study of intima-media thickness and plaques in the carotid artery. Vasc Biol, 16:462-70.
Van Merode T, Brands PJ, Hoeks AP, et al. 1993. Faster ageing of the carotid artery bifurcation in borderline hypertensive subjects. J Hypertens, 11:172-6.

Wang JG, Staessen JA, Li Y, et al. 2006. Carotid intima-media thickness and hypertensive treatment: a meta-anlysis of randomized controlled trials. Stroke, 37:1933-40.

Willians MA, Fleg JL, Ades PA, et al. 2002. Secondary prevention of coronary heart disease in the elderly (with emphasis on patients $\geq 75$ years of age). An American Heart Association scientific statement from the Council on Clinical Cardiology Subcommittee on Exercise, Cardiac Rehabilitation and Prevention. Circulation, 105:1635-43.

Wilson PW, Anderson KM, Harris T, et al. 1994. Determinants of change in total cholesterol and HDL-c with age: the Framingham Study. Gerontol, 49: 252-7.

Wilson PWF, Hoeg JM, D'Agostino RB, et al. 1997. Cumulative effects of high cholesterol levels, high blood pessure, and cigarette smoking on carotid stenosis. $N$ Engl J Med, 8: 516-22.

Wilt JT, Rubins HB, Robins SJ, et al. 1997. Carotid atherosclerosis in men with low levels of HDL cholesterol. Stroke, 28:1919-25.

Zanchetti A. 1996. Antiatherosclerotic effects of antihypertensive drugs: recent evidence and ongoing trials. Clin Exper Hypertens, 18:489-99. 